\title{
Splenomesenteric vein: formally recognising a clinically relevant section of the portal venous drainage system
}

\author{
B. Benninger 1 , 2, 3, 4, 5, 6, 7, 8 \\ ${ }^{1}$ Department of Medical Anatomical Sciences, Western University of Health Sciences, COMP-Northwest, \\ Lebanon, United States \\ 2Department of Neuromuscular Medicine, Western University of Health Sciences, COMP-Northwest, Lebanon, \\ United States \\ ${ }^{3}$ Department of Family Practice, Western University of Health Sciences, COMP-Northwest, Lebanon, United States \\ ${ }^{4}$ Samaritan Health Services Orthopaedics, Residency Faculty, Corvallis, United States \\ 5Samaritan Health Services General Surgery, Residency Faculty, Corvallis, United States \\ ${ }^{6}$ Department of Oral Maxillofacial Surgery, Oregon Health and Science University, Portland, United States \\ ${ }^{7}$ Department of Surgery, Oregon Health and Science University, Portland, United States \\ ${ }^{8}$ Department of Orthopaedics and Rehabilitation, Oregon Health and Science University, Portland, United States
}

[Received 3 May 2012; Accepted 19 June 2012]

Background and aims: The objective of this study was to identify and examine a common vein in the portal system that is not consistently named, and when named, to assess whether fundamental concepts were applied in the process of naming. Essentially, the portal venous system drains 3 regions of the gastrointestinal system into 3 major veins (superior mesenteric - SMV, splenic $S V$, and inferior mesenteric - IMV) ultimately forming the portal vein (PV). The $S M V$ is formed from midgut veins generally representing the right side of the abdomen. The IMV is formed from hindgut veins generally representing the left side of the lower abdomen and pelvis, classically draining into the SV. The SV is formed from the foregut veins and generally accepts the IMV. The SV then joins the superior mesenteric vein to become the PV.

Materials and methods: Sixty cadavers were dissected to observe the frequency of this morphology. Current anatomy and atlas texts were reviewed to identify the morphology and nomenclature.

Results: Observations from this study identified a vein being formed from the convergence of the SV and IMV the author named "splenomesenteric vein", which joins the superior mesenteric to form the PV.

Conclusions: These findings suggest re-evaluating the morphology and nomenclature of this structure because of the pathology and clinical relevance of this area. (Folia Morphol 2013; 72, 1: 63-66)

Key words: portal venous system, dynamic hepatobiliary scintigraphy, portal vein formation, splenic vein, inferior mesenteric vein

\section{INTRODUCTION}

Classically, when a named vein joins or merges with another named vein, the newly combined structure takes on a separate name. Often if right and left similar named veins are involved, the joining is renamed the 'common' or is given its own isolated name of the two structures (e.g. right hepatic vein and left hepatic vein form the common hepatic or

Address for correspondence: B. Benninger, MD, MSc, Western University of Health Sciences, COMP, Northwest, Oregon Health and Sciences University, Lebanon, OR, 97355, United States, e-mail: bbenninger@westernu.edu 
simply hepatic vein). An overwhelming number of surgical and clinical anatomy textbooks and atlases describe and illustrate two very distinct named veins: the inferior mesenteric vein (IMV) and the splenic vein (SV) $[1-3,5,6,8,9,11,12,14,16-28]$. Apart from an anomaly, the inferior mesenteric joins or merges with the SV on a relatively consistent basis. After the IMV joins the SV, there is up to three inches of vein before it joins the superior mesenteric vein (SMV) to form the portal vein. If one was to apply fundamental concepts to the venous structure formed from the union of these two distinctly different named veins, the new venous structure should be given separate names especially if there is clinical relevance. There are several clinical conditions and imaging modalities affecting and revealing the anatomy of the portal venous system. Following two decades of identifying the morphology of the portal venous region, the author investigated this unnamed venous structure. The objective of this study is to identify and formally recognise a vein, which is part of the portal venous system that is associated with clinical procedures, in order to improve clinical and anatomical description.

Pancreatitis may lead to vascular complications including venous occlusion. The SV is particularly vulnerable. Pancreatic cancer and cholangiocarcinoma can affect the 'splenomesenteric' vein due to tumour extension and metastasis. Septic thrombosis may occur in people with appendicitis, diverticulitis, cholecystitis, and inflammatory bowel disease. Hepatocellular carcinomas are usually not resectable when they initially present $[4,15]$. The portal vein is involved via invasion in approximately $70 \%$ of cases. The portal venous system can be highlighted using varied imaging modalities, allowing evaluation of the portal venous pathology, aiding diagnosis, and providing treatment options $[7,10,13]$. To make a definitive diagnosis, the architecture of the anatomy must be detailed and understood (Fig. 1).

\section{MATERIALS AND METHODS}

A literature search was conducted using surgical and anatomical textbooks, atlases, specialist texts, and journals to investigate whether or not there was a consistent naming of the vein formed from the union of the SMV and SV prior to the forming of the portal vein.

This study dissected 60 human embalmed cadavers (ages 45-89, avg. 82.4) to analyse the portal venous system, with attention to the union of the SMV and SV forming another vein before it unites

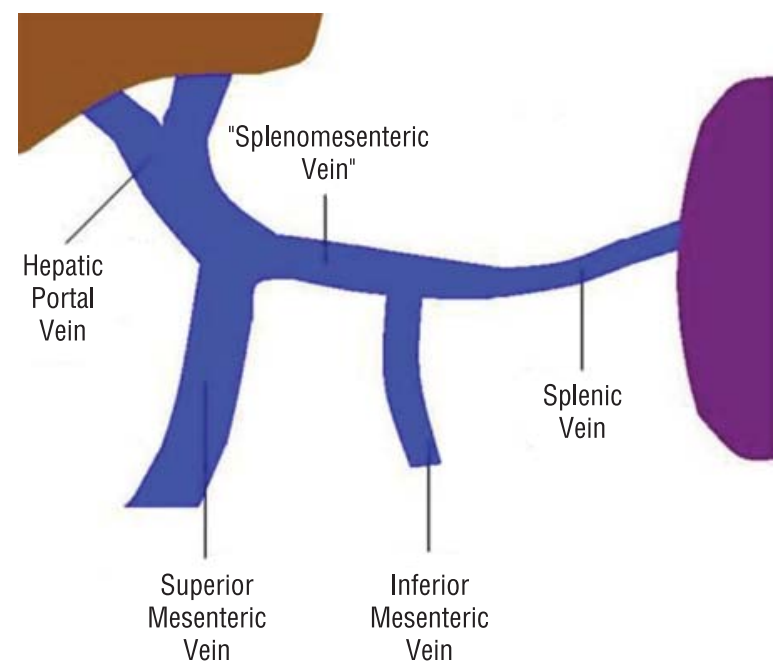

Figure 1. Animated drawing of the portal venous system representing classic morphology; displaying the union of the inferior mesenteric and splenic veins to form the splenomesenteric vein.

with the SMV to form the portal vein. There must be at least $3 \mathrm{~cm}$ length beyond the union of the IMV and SV prior to joining the SMV to be considered the 'splenomesenteric' vein. Exclusion factors included previous abdominal surgery involving the venous architecture (Fig. 2).

\section{RESULTS}

The literature search did not reveal a separate named vein for the structure formed from the union of the IMV and SV; 53 out of 60 cadavers revealed a portal venous system. Seven cadavers had previous surgery or pathology with grossly distorted portal venous system architecture. This study revealed, in 53 cadaver dissections, a consistent pattern of a venous structure forming from the union of the IMV and SV. The incidence of the IMV joining the SV was $71.7 \%$ (length greater than $3 \mathrm{~cm}$ ). The IMV directly joined the SMV in $18.9 \%$ (failing to join the SV at all) of cases to form the 'common mesenteric' vein. The IMV joined the junction (or 'crotch') of the SMV and SV in $9.4 \%$ of cases to form the portal vein (Fig. 3).

\section{DISCUSSION}

Anatomical textbooks, atlases, and journals describe and illustrate the union of the IMV and SV $[1-3,5,6,8,9,11,12,14,16-28]$. No name is given to the venous structure formed from the union of the above two veins. This is strongly out of character if one follows fundamental concepts in anatomy. Due to the clinical relevance to pro- 


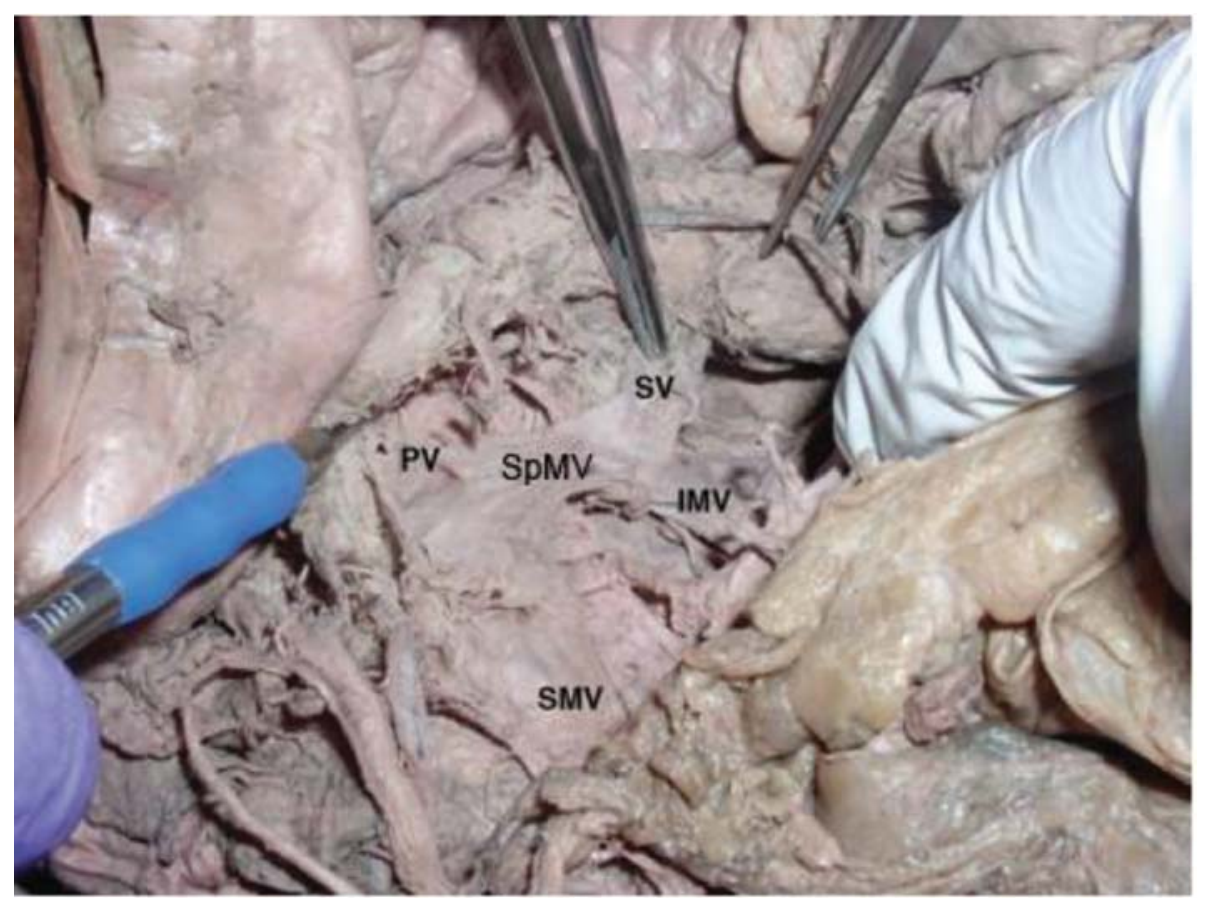

Figure 2. Cadaver dissection — portal venous system representing classic morphology; SMV — superior mesenteric vein; SpMV — splenomesenteric vein; PV — portal vein; IMV — inferior mesenteric vein; SV — splenic vein.

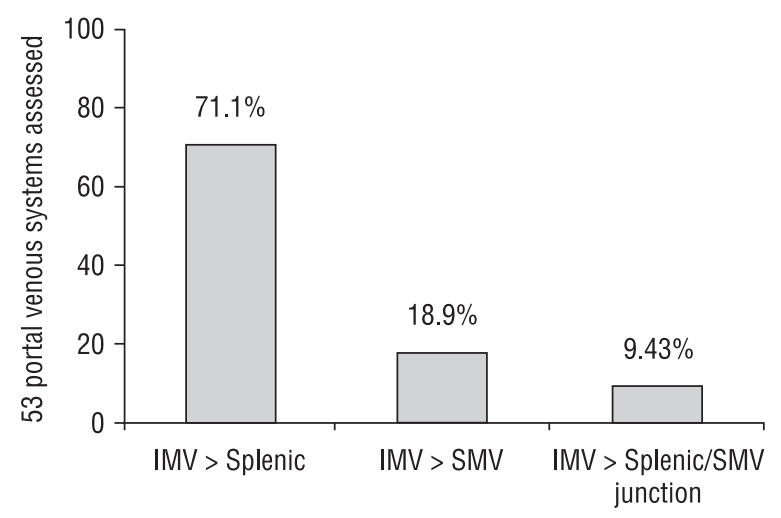

Figure 3. Graph of differing morphologies of the inferior mesenteric vein (IMV). The IMV joined the splenic vein in 38 portal venous systems (71.7\%); the IMV joined the superior mesenteric vein (SMV) in 10 portal venous systems $(18.9 \%)$; the IMV joined the junction of the splenic vein and the SMV in 5 portal venous systems $(9.43 \%) ; \mathrm{N}=53$.

cedures (surgery, embolisation, etc.) and the importance of describing pathology using accurate anatomy, the naming of a vein in a dynamic area of the body is paramount. This study suggests that the structure formed from the union of the IMV and SV could be given the formal name of the 'splenomesenteric' vein due to its high percentage of incidence and clinical relevance, or informally Benninger's vein.

\section{CONCLUSIONS}

These findings suggest re-evaluating the morphology and nomenclature of this structure because of the pathology and clinical relevance of this area.

\section{ACKNOWLEDGEMENTS}

The authors are grateful to all the donor-cadaver-patients whose gift enabled this study to be conducted in The McDaniel Clinical Anatomy Research Lab.

\section{REFERENCES}

1. Abrahams PH, Boon JM, Spratt JD (2008). McMinn's clinical atlas of human anatomy. Mosby Elsevier, Philadelphia, pp. 238-244.

2. Agur AMR, Dalley AF (2009) Grant's atlas of anatomy, $12^{\text {th }}$ Ed. Lippincott, Williams \& Wilkins, Philadelphia, pp. 125-127, 160.

3. Akbar SA, Narra V, Madrazo B, Jafri SZH, Salem R, Bis K (2007) Pictorial essay: multimodality imaging of the portal venous system. Int J Radiol, 7: DOI: 10.5580/1 b87.

4. Aussilhou B, Lesurtel M, Sauvanet A, Farges O, Dokmak S, Goasguen N, Silbert A, Vilgrain V, Belghiti J (2008) Right portal vein ligation is as efficient as portal vein embolization to induce hypertrophy of the left liver remnant. The Society for Surgery of the Alimentary Tract, 12: 297-303.

5. Chung KW (2008) Gross anatomy. $6^{\text {th }}$ Ed. Lippincott, Williams, \& Wilkins, Philadelphia, pp. 206-209.

6. Clemente CD (1997) Clemente anatomy. $4^{\text {th }}$ Ed. Lippincott Williams \& Wilkins, Philadelphia, pp. 196-197, 201, 218. 
7. Daffner RH (1999) Clinical radiology: the essentials. Lippincott, Williams \& Wilkins, Philadelphia, pp. 329-333.

8. Drake RL, Vogl AW, Mitchell AWM (2010) Gray's anatomy for students. $2^{\text {nd }}$ Ed. Churchill Livingstone, Philadelphia, pp. 322-340.

9. Drake RL, Vogl AW, Mitchell AWM, Tibbits RM, Richardson PW (2008) Gray's atlas of anatomy. Churchill Livingstone, Philadelphia, pp. 152-154, 169-172.

10. Eisenberg RL (2003) Clinical imaging. $4^{\text {th }}$ Ed. Lippincott, Williams \& Wilkins, Philadelphia, pp. 580-585.

11. Ellis H (2006) Clinical anatomy: applied anatomy for students and junior doctors. $11^{\text {th }}$ Ed. Blackwell Publishing Ltd, Massachusetts, pp. 87, 104.

12. Federative Committee on Anatomical Terminology (1998) Terminologia Anatomica. Thieme Stuttgart, New York, pp. 99.

13. Fleckenstein P, Tranum-Jensen J (2001) Anatomy in diagnostic imaging. $2^{\text {nd }}$ Ed. Blackwell Publishing, Munksgaard, pp. 335, 358.

14. Gilroy AM, MacPherson BR, Ross LM (2008) Atlas of anatomy. Thieme Medical Publishers, New York, pp. 218-221.

15. Giorgio G, Greget M, Oussoultzoglou E, Rosso E, Bachellier P, Jaeck D (2008) Preoperative contralateral portal vein embolization before major hepatic resection is a safe and efficient procedure: a large single institution experience. Surgery, 143: 476-482.

16. Gosling JA, Harris PF, Humpherson JR, Whitmore I, Willian PLT (2008) Human anatomy. $5^{\text {th }}$ Ed. Mosby Elsevier, Spain, pp. 139, 161-170.
17. Hall-Craggs ECB (1990) Anatomy as a basis for clinical medicine. $2^{\text {nd }} E d$. Urban \& Schwarzenberg, Baltimore, pp. 254, 260-261, 277-285.

18. Hartwig W (2008) Fundamental anatomy. Lippincott, Williams \& Wilkins, Philadelphia, pp. 103-105.

19. Jacob S (2002) Atlas of human anatomy. Churchill Livingstone, Edinburgh, pp. 118-120.

20. Moore KL (2007) Essential clinical anatomy. $3^{\text {rd }}$ Ed. Lippincott Williams \& Wilkins, Philadelphia, pp. 168-173.

21. Moore KL, Dalley AF, Agur AMR (2010) Clinically oriented anatomy. 5th Ed. Lippincott, Williams, \& Wilkins, Philadelphia, pp. 265-278.

22. Netter FH (2006) Atlas of human anatomy. $5^{\text {th }}$ Ed. Saunders, Philadelphia, pp. 287-294.

23. Rohen J, Yokochi C, Lutjen-Drecoll E (2006) Color atlas of anatomy. $6^{\text {th }}$ Ed. Schattauer, New York, pp. 300, 316-318.

24. Sinnatamby CS (2006) Last's anatomy regional and applied. $11^{\text {th }} \mathrm{Ed}$. Churchill Livingstone, Edinburgh, pp. 276-281.

25. Slaby FJ, McCune SK, Summers RW (1994) Gross anatomy in the practice of medicine. Lea \& Febiger, Philadelphia, pp. 459-460, 466.

26. Snell RS (2007) Clinical anatomy by systems. Lippincott, Williams \& Wilkins, Philadelphia, pp. 236-237.

27. Stranding S (2005) Gray's anatomy: the anatomical basis of clinical practice. $40^{\text {th }}$ Ed. Elsevier, Philadelphia, pp. 1112, 1187, 1191-1195.

28. Tank PW, Gest TR (2009) Atlas of anatomy. Lippincott, Williams \& Wilkins, Philadelphia, pp. 239-241. 